\title{
Attitudes of professionals of the Network of Psychosocial Attention to mental illness
}

\author{
Atitudes de profissionais da Rede de Atenção Psicossocial frente ao adoecimento mental
}

Aline Mara Gonçalves ${ }^{1}$, Sueli de Carvalho Vilela ${ }^{1}$, Fábio de Souza Terra ${ }^{1}$

Objective: to investigate the attitudes of professionals of the Network of Psychosocial Attention to mental illness. Methods: cross-sectional and analytical study. Two instruments were used: the characterization questionnaire and the Opinions Scale about Mental Illness, answered by 80 employees of the Psychosocial Attention Network. For counting the obtained points, pre-established formulas were used; and for correlations and associations, non-parametric tests according to the normality of the data. Results: the attitudinal profile denominated Authoritarianism was characterized by a higher average in the population, followed by the Social Restriction and Etiology of Mental Effort profiles. It was also observed that the variables schooling, working time in mental health services and monthly family income showed significant correlations in relation to the types of attitudes. Conclusion: the attitudinal profile of the studied population reflects predominantly authoritarian, restrictive and discriminatory attitudes.

Descriptors: Attitude; Workers; Mental Health.

Objetivo: investigar as atitudes de profissionais da Rede de Atenção Psicossocial frente ao adoecimento mental. Métodos: estudo transversal e analítico. Utilizaram-se dois instrumentos: o questionário de caracterização e a Escala de Opiniões sobre a Doença Mental, respondidos por 80 trabalhadores da Rede de Atenção Psicossocial. Para contagem dos pontos obtidos, foram utilizadas fórmulas preestabelecidas; e para correlações e associações, testes não paramétricos conforme a normalidade dos dados. Resultados: o perfil atitudinal denominado Autoritarismo destacou-se por apresentar maior média na população, seguido dos perfis Restrição Social e Etiologia do Esforço Mental. Observou-se também que as variáveis escolaridade, tempo de trabalho em serviços de saúde mental e renda familiar mensal apresentaram correlações significativas em relação aos tipos de atitudes. Conclusão: o perfil atitudinal da população estudada reflete atitudes predominantemente autoritárias, restritivas e discriminatórias.

Descritores: Atitude; Trabalhadores; Saúde Mental.

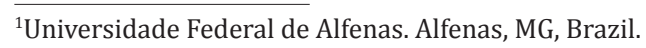




\section{Introduction}

The Psychiatric Reform emerged in Brazil in a period of great social mobilization for democracy, strongly influenced by the reform movements of other countries, mainly by the Italian experience. Constituted from the denial of the asylum paradigm and the need to propose a differentiated way of dealing with insanity, focused on the psychosocial care model, the Psychiatric Reform includes overcoming the old model through extra hospital care services, living spaces, decent housing and family, guaranteeing the execution of an innovative therapeutic project ${ }^{(1)}$.

However, understanding this process as merely a society without psychiatric hospitals does not guarantee the overcoming of the hegemonic model, once depending on the discursive practices adopted, that same society would remain strongly asylum adept. Thus, it is important that the professionals of the area adopt a new attitude, breaking with the culture of the asylum, aimed at the rehabilitation of psychiatric patients $^{(2)}$.

That said, it is necessary to conceptualize the term attitude, which presents several definitions. Thus, as the predisposition to respond, the attitude can be described according to the Social Psychology referential, consistently, favorably or unfavorably, to a given object ${ }^{(3)}$. So, the attitude is seen as a predisposition to a particular action or action. It is essentially related to opinions, beliefs and feelings directed at an object, person or situation, defined as mental illness in this study, being the most distinctive and indispensable concept of contemporary social psychology $y^{(4)}$.

In the Psychosocial Care Network, professionals, faced with the renewal of the care model, sometimes present conflicts between practice, the historical experience with the mentally ill, and the new assistential political discourse in mental health ${ }^{(5)}$. In this context, the relationship of the professionals' attitudes to those with mental disorders has been considered a barrier to the process of psychiatric reform, making it difficult to improve mental health care and contributing to the stigma experienced by them ${ }^{(6)}$.

Thus, investigating the attitudes of professionals of the Network of Psychosocial Attention to mental illness has great relevance, considering contributions to professional improvement to improve these attitudes in the work environment, with a positive impact on health care provided and, consequently, bringing best results for service users. In addition, this research represents an important academic collaboration due to the lack of studies related to this topic.

Thus, this study aimed at investigating the attitudes of professionals of the Network of Psychosocial Attention to mental illness.

\section{Methods}

A cross-sectional, analytical study, developed in the first half of 2014 in the services that assist people with mental disorders: a Psychosocial Care Center II, a Coexistence Center, seven Therapeutic Residency Services II, an outpatient clinic that provides clinical and psychological care, two Reference Centers for Social Assistance, a Specialized Referral Center for Social Assistance and twelve Family Health Strategies, all from a medium-sized municipality in the south of Minas Gerais, Brazil.

The total population of professionals included in the Municipal Psychosocial Assistance Network was 103 employees. It was adopted as an inclusion criterion to work in the services of the psychosocial care network in direct contact with these users; and exclusion criteria: to be on vacation or on medical leave in the period of data collection. Of these professionals, five were away on medical leave or on vacation, and $18 \mathrm{did}$ not agree to respond to the survey.

The sample consisted of 80 employees, thirty-four professionals with college degree, among 16 nurses, seven psychologists, four social workers, four physicians, two occupational therapists and one pharmacist; 46 with technical, middle and elementary lev- 
el, consisting of 21 caregivers, eight general service employees, five nursing technicians, four receptionists, three therapeutic workshop monitors, two social agents, two drivers and a pharmacy clerk.

The data were collected through two instruments: a semi-structured questionnaire to characterize the participants, prepared by the researchers, containing eight questions, six of which were sociodemographic characteristics (gender, age, marital status, schooling, monthly family income and religious belief) and two concerning professional characteristics (job function and working time in mental health).

To evaluate the professionals' attitudes toward mental illness, the Opinions about Mental Illness Scale ${ }^{(7)}$ was used, it is a public domain scale, translated and validated for Brazilian culture, with the denomination Opinion on Mental Illness ${ }^{(3)}$.

The scale is composed of 51 Likert-type statements and their response options vary according to a progressive sequence of six points of agreement, ranging from "strongly agree" to "strongly disagree". These statements are grouped into seven factors: Authoritarianism, Benevolence, Ideology of Mental Hygiene, Social Restriction, Interpersonal Etiology, Etiology of Mental Effort and Minority Vision ${ }^{(3)}$.

The data, obtained by the instrument applications, were transcribed into a Microsoft Excel spreadsheet database version 2010, which was prepared by double typing and then transported to the Software Statistical Package for Social Science version 17.0 to carry out the relevant analyzes.

For the counting of the points obtained with the application of the scale, pre-established formulas were used, giving scores for each professional in the seven factors ${ }^{(3)}$.
The verification of normality by the Shapiro Wilk test demonstrated that there was no normality for any of the data, thus nonparametric measurements were used for correlation and association. As for the correlation between the scale factors and the numerical variables (age, educational level, monthly family income, working time in Mental Health services), the Spearman Coefficient was used. The Mann-Whitney test to establish the association between sex and scale factors was used. The Kruskal-Wallis test was used to associate the variables marital status and categorization of the profession with the Factors of the Opinion Scale against Mental Illness. For the Multiple Comparison Test, the Dunn Test would be used; however, there was no significant association between the variables. The significance level of 5.0\% was adopted. The results were systematized in the form of tables for better data exposure.

The study complied with the formal requirements contained in national and international standards for research involving human beings.

\section{Results}

The prevalence of female professionals (80.0\%), aged between 41 and 50 years (36.0\%), married (51.3\%), was predominant among the professionals of the Psychosocial Care Network of the Municipality, of the Catholic religion (65.0\%) and presenting monthly family income of four to five minimum wages (38.7\%). The aspects related to the professional characteristics evidenced that the most professional category is the one of professionals with college degree $(42.5 \%)$, followed of the fundamental level (38.8\%); with work time of one to five years (51.3\%).

Table 1 - Average values for attitudes towards mental illness of the mental health professionals

\begin{tabular}{|c|c|c|c|c|c|c|c|}
\hline $\begin{array}{l}\text { Descriptive } \\
\text { statistics }\end{array}$ & Authoritarianism & Benevolence & $\begin{array}{c}\text { Ideology mental } \\
\text { hygiene }\end{array}$ & $\begin{array}{l}\text { Social } \\
\text { restriction }\end{array}$ & $\begin{array}{c}\text { Interpersonal } \\
\text { Etiology }\end{array}$ & $\begin{array}{l}\text { Etiology mental } \\
\text { effort }\end{array}$ & $\begin{array}{l}\text { Minority } \\
\text { vision }\end{array}$ \\
\hline Average & 6.65 & 5.96 & 3.89 & 6.58 & 4.43 & 6.31 & 6.06 \\
\hline Medium & 6.50 & 6.00 & 4.00 & 7.00 & 5.00 & 6.00 & 6.00 \\
\hline Minimum & 3.00 & 1.00 & 1.00 & 3.00 & 1.00 & 2.00 & 1.00 \\
\hline Maximum & 10.00 & 8.00 & 9.00 & 10.00 & 9.00 & 10.00 & 10.00 \\
\hline
\end{tabular}


The attitudinal profile denominated Authoritarianism was characterized by a higher average (6.650) in the population, followed by the Social Restriction profile (6.580), while the attitude corresponding to the Etiology of Mental Hygiene presented a lower average compared to the others (Table 1).

Regarding correlations analyzes with sociodemographic and professional data, the values described in Table 2 were found.

Authoritarianism, social restriction and mental effort etiology presented correlations of weak magnitudes $(-0.334)$, moderate $(-0.435)$ and strong $(-0.582)$, respectively, in relation to the educational variable. These data suggest that higher educated professionals were less favorable to negative attitudes.

Attitudinal profiles, called Social Restriction and Etiology of Mental Effort presented, although weakly, a significant correlation, in relation to the working time variable in mental health $(-0.344$ and -0.276 , respectively).
The same variable had a correlation with the Ideology of Mental Hygiene factor (0.232). From these results, the working time in the area is understood to be correlated with the lowest indexes of restrictive and discriminatory attitudes and with the most favorable attitudinal profile.

When correlated with the etiology factor of mental effort and social restriction, the monthly family income variable presented a significant result (-0.151 and -0.147). The data suggest that the higher the family income, the lower the tendency of this professional to present discriminatory and restrictive behaviors.

Regarding the association tests, the attitudinal profiles did not present significant associations with the mentioned variables.

The same variable had a correlation with the Ideology of Mental Hygiene factor (0.232). From these results, the working time in the area is understood to be correlated with the lowest indexes of restrictive and discriminatory attitudes and with the most favorable attitudinal profile.

Table 2 - Correlation between the numerical variables and the values of the scale of opinions on mental illness

\begin{tabular}{lcccc}
\hline Variables & Age* & Education* & Monthly family income* & $\begin{array}{c}\text { Working time in mental } \\
\text { health service* }\end{array}$ \\
\hline \multirow{2}{*}{ Authoritarianism } & $\mathrm{r}=0.138$ & $\mathrm{r}=-0.334$ & $\mathrm{r}=-0.150$ & $\mathrm{r}=-0.151$ \\
& $\mathrm{p}=0.223$ & $\mathrm{p}=0.002^{* *}$ & $\mathrm{p}=0.183$ & $\mathrm{p}=0.181$ \\
Benevolence & $\mathrm{r}=0.195$ & $\mathrm{r}=-0.149$ & $\mathrm{r}=-0.049$ & $\mathrm{p}=0.115$ \\
& $\mathrm{p}=0.084$ & $\mathrm{p}=0.188$ & $\mathrm{p}=0.666$ & $\mathrm{r}=0.2311$ \\
Ideology of mental hygiene & $\mathrm{r}=0.120$ & $\mathrm{r}=-0.100$ & $\mathrm{r}=-0.118$ & $\mathrm{p}=0.039^{* *}$ \\
& $\mathrm{p}=0.290$ & $\mathrm{p}=0.379$ & $\mathrm{p}=0.296$ & $\mathrm{r}=-0.344$ \\
Social restriction & $\mathrm{r}=-0.003$ & $\mathrm{r}=-0.435$ & $\mathrm{r}=-0.147$ & $\mathrm{p}=0.002^{* *}$ \\
Interpersonal Etiology & $\mathrm{p}=0.976$ & $\mathrm{p}=0.002^{* *}$ & $\mathrm{p}=0.042^{* *}$ & $\mathrm{r}=-0.065$ \\
& $\mathrm{r}=0.190$ & $\mathrm{r}=-0.091$ & $\mathrm{r}=-0.052$ & $\mathrm{p}=0.566$ \\
Etiology of mental effort & $\mathrm{p}=0.092$ & $\mathrm{p}=0.420$ & $\mathrm{p}=0.645$ & $\mathrm{r}=-0.276$ \\
Minority vision & $\mathrm{r}=-0.034$ & $\mathrm{r}=-0.582$ & $\mathrm{r}=-0.151$ & $\mathrm{p}=0.013^{* *}$
\end{tabular}




\section{Discussion}

The study presented limitations regarding the transversal design and the reduced number of samples, which did not allow the analysis of attitude changes over time and restricted the extrapolation of the data. Therefore, new studies, longitudinal and with larger populations, are suggested to better identify the professionals' attitudinal profile.

Before the results, the study revealed a less favorable attitudinal profile. Authoritarianism showed a higher average (6.65), followed by the factors Social Restriction (6.58), Etiology of Mental Effort (6.31) and Minority Vision (6.06). These factors are characteristic, respectively, of attitudes related to the vision of irrecoverability and dangerousness of the mentally ill; to the understanding of patient as a person incapable of living in society and, finally, of discriminatory visions, emphasizing inferiority and difference ${ }^{(8)}$.

The authoritarian role of vigilance, control and repression, developed in the mental hospital, is characteristic of the beginning of Brazilian psychiatry, and should be replaced by therapeutic interpersonal relations based on light care technologies and with the support in knowledge ${ }^{(9)}$. Authoritarian and discriminatory attitudes lead to social exclusion ${ }^{(10)}$, which contrasts current precepts and ideologies that suggest more egalitarian relations of valorization of the subject and their potentialities, as well as overcoming tutelary practices ${ }^{(1)}$.

With similar results, research conducted with professionals of emergency health services evidenced the predominance of more negative attitudes toward the mentally ill. In addition, it was found that nursing professionals, when compared to professionals of services specifically aimed at mental health, presented a more stereotyped view of these patients. This result would refer to the small contact these professionals have with these users ${ }^{(11)}$.

This type of stigmatized vision can generate worse results in health care. According to a study carried out with third-year nursing students, feelings of fear and the idea of dangerousness of the mentally ill were preponderant, which would lead to unsatisfactory experience in mental health practice both for students and for the users of health services themselves ${ }^{(12)}$.

Other studies that sought to assess attitudes toward mental illness in emergency and emergency care professionals ${ }^{(11)}$, nursing students ${ }^{(12)}$, and mental health professionals ${ }^{(13)}$ also pointed to a less favorable attitudinal profile. However, research with nurses showed that, in general, these professionals present more positive attitudes toward mental illness ${ }^{(14)}$. This result may be related to the educational actions of the program to combat stigmatization of the mental patient, called Time To Change, implemented in the country of origin of the research ${ }^{(15)}$.

In view of these realities, information is needed to change behaviors ${ }^{(4)}$. However, when it comes to the Brazilian reality, this process has not yet been consolidated. In research carried out to understand the perception of nursing professionals about the changes in mental health care, they point out advances in this area, however, still fragile, showing that psychiatric reform is far from being fulfilled ${ }^{(16)}$.

The results also pointed to the Benevolence factor, as a favorable attitude, presenting a higher average (5.96), reflecting a kind and paternalistic view of the patient, based on personal care and comfort, due to his unhappiness. The origin of these attitudes derives from religious, moral, humanistic and non-scientific aspects ${ }^{(8)}$.

Although the study did not statistically establish this relationship, research on attitudes toward mental illness, performed exclusively with women, pointed out that they have a greater tendency towar$\mathrm{ds}$ benevolent attitudes ${ }^{(17)}$. It is inferred, then, that the fact that the population, formed mainly by female individuals, may be related to the average of this factor. Still in this context, one should avoid turning negative attitudes into benevolence in the charitable sense, that is, paternalistic, protective and moralistic, since this would be equally negative, since the autonomy of 
these individuals would not be stimulated ${ }^{(18)}$.

Interpersonal Etiology presented the second lowest average (4.43) in the population and reflects the conviction that mental illness originates through interpersonal experience, particularly the deprivation of parental affection during childhood ${ }^{(3)}$.

A study carried out with nurses has shown that they present conflicts of opinion regarding the etiology of mental illness, some attributed to genetic factors and others to psychological issues ${ }^{(14)}$. These conflicts may be related to the difficulty of understanding mental illness as a disease like the others, with complex rather than unidimensional causes. Some types of beliefs about the etiology of mental illness can have a beneficial effect in combating the stigmatization of mental illness. The conception of mental illness, caused by genetic and biological issues as well as psychosocial issues, helps to understand mental illness as pathology similar to any other, reducing the idea of fear, dangerousness and discriminatory attitudes ${ }^{(19)}$. Thus, attributing mental illness exclusively to the emotional issues of childhood would also have deleterious effects on the care provided.

The Ideology of mental hygiene factor had the lowest average in the general population (3.89). This attitude reflects the vision of orientation opposite to that projected by the Authoritarianism factor and represents the adaptation of the medical model to the psychiatric problems. Furthermore, it ponders the idea that mental illness is a disease like any other ${ }^{(5)}$.

A study with emergency services professionals has shown similar results, found in the attitudinal profile characteristics of this population as little conscious of the factors that trigger mental illness ${ }^{(11)}$, even if they are not specific services of the psychosocial care network. Substitutive services, under the psychosocial rehabilitation proposal, seek to define a new social place for the treatment and rehabilitation of people with mental suffering, promoting actions aimed at the process of social integration ${ }^{(20)}$. In this way, attitudes that distance themselves from this model, especially in these services, make this process even more difficult.

Regarding the correlations, the variables monthly family income, schooling and working time in mental health services presented significant results with some attitudinal profiles. The factors Etiology of Mental Effort and Social Restriction presented an inverse correlation with the monthly family income variable, allowing the inference that the higher the family income, the lower the tendencies to restrictive and discriminatory attitudes.

In a population-based study, similar results were found, and better attitudes were correlated with a higher socioeconomic level, which may be justified by greater access to information on mental disor$\operatorname{ders}^{(15)}$. However, in a study carried out with rural women, an inverse result was evidenced, indicating a trend of more negative attitudes correlated with higher family income. This discrepancy of results is attributed to the cultural differences existing between societies $^{(17)}$.

As for the variable education, it is pointed out that there is a relationship pointing to it as a way of acquiring new knowledge and, therefore, as a guiding basis for professionals' attitudes ${ }^{(9)}$. This is consistent with the results of a study carried out to evaluate the impact of academic training in nursing in relation to Authoritarianism, in which it was observed that the graduation provided experiences that enabled changes in the understanding of mental illness by students and, as a consequence, in the posture of these front to situations involving people with mental disorders ${ }^{(10)}$.

On the other hand, a study carried out with a similar objective, but with students of Nursing, Medicine and Psychology, concluded that academic instruction did not motivate a significant change in students' attitudes towards mental disorder presented, and this should be improved, since, even after influence, they may retain some prejudices and attitudes that will influence professional practice ${ }^{(6)}$.

The discrepancies between these two studies may be brought about by the conception used in the education offered. From the experience of one of the 
authors, schooling can interfere with the attitude of students towards mental illness, since the conceptions and fears present at the beginning of the disciplines are demystified at the end of the latter.

The variable working time in mental health services presented an inverse relationship with the less favorable attitudinal profiles and direct with the more favorable Mental Hygiene Ideology. These results allow us to understand the importance of greater contact with patients with mental disorders for rupture with stigmatizing values. This theme was addressed in other studies ${ }^{(10,18)}$. In research conducted with professional nurses of mental health services, attitudes that are more positive were correlated with longer working time in mental health ${ }^{(14)}$. In addition, research conducted with nursing students, before and after the experience in psychiatry, pointed out that greater contact with this reality contributed to the development of more favorable attitudes ${ }^{(11)}$.

Direct contact with people with mental disorders would then be more effective in combating negative attitudes than awareness only through educational materials. Thus, this has been recommended as a form of effective intervention, since when a person relates mental illness to an individual and not simply to a disorder, it tends to present better attitudes ${ }^{(18)}$.

In view of these results, it should be pointed out that a network of mental health care, based on the principles of the psychosocial care model, requires greater investment in the training of the professionals who will work in these services, since they are part of a change still in progress ${ }^{(16)}$. Therefore, as observed in a study that sought to identify the existence of a relationship between attitudinal profiles and the pleasure/suffering dynamic in workers in mental health services $^{(13)}$, it is suggested that these professionals be offered professional improvement programs and training for that through greater contact and knowledge about mental illness. Therefore, attitudinal profiles may be more consonant with the new mental health proposals.

Therefore, these findings may contribute to a better understanding of the attitudes of these professionals towards mental illness, as well as the factors that may influence them, being a starting point to combat attitudes that do not fit the model of assistance currently advocated.

\section{Conclusion}

The attitudinal profile of the population studied still reflects predominantly authoritarian, restrictive and discriminatory attitudes. It was also verified that the variables monthly family income, schooling and work time in mental health service showed a positive influence on attitudes towards mental illness, presenting an inverse correlation with the less favorable attitudinal profiles and direct with the more favorable profile.

\section{Collaborations}

Gonçalves AM contributed in designing the project, analyzing and interpreting the data. Vilela SC contributed in the writing of the article and critical review relevant of the intellectual content. Terra FS contributed in the final approval of the version to be published.

\section{References}

1. Argiles CTL, Kantorski LP, Willrich JQ, Antonacci MH, Coimbra VCC. Redes de sociabilidade: construções a partir do serviço residencial terapêutico. Ciênc Saúde Coletiva. 2013; 18(7):204958. doi: http://dx.doi.org/10.1590/S141381232013000700020

2. Willrich JQ, Kantorski LP, Antonacci MH, Cortes JM, Chiavagatti FG. Da violência ao vínculo: construindo novos sentido para a atenção à crise. Rev Bras Enferm. 2014; 67(1):97-103. doi: http:// dx.doi.org/10.5935/0034-7167.20140013

3. Rodrigues CRC, Comparacion de actitudes de estudiantes de medicina brasilenos y espanoles hacia la enfermidade mental. Actas Loso-Esp Neurol Psiquiatr Ci Afines. 1992; 20(1):30-41. 
4. Cavazza, N. Psicologia das atitudes e das opiniões. São Paulo: Loyola; 2008.

5. Lima DU, Garcia APRF, Toledo VP. Understanding the nursing team in the assistance to the schizophrenic patient. Rev Rene [Internet]. 2013 [cited 2017 Jun 13]; 14(3):503-11. Available from: http://www.revistarene.ufc.br/revista/index. $\mathrm{php} /$ revista/article/view/831

6. Ferreira FN, Fernandino DC, Souza GRM, Ibrahim TF, Fukino ASL, Araújo NC, et al. Avaliação das Atitudes de Estudantes da Área da Saúde em relação a Pacientes Esquizofrênicos. Rev Bras Educ Méd. 2015; 39(4):542-9. doi: http://dx.doi. org/10.1590/1981-52712015v39n4e01562014

7. Cohen J, Struening EL. Opinions about mental illness in the personnel of two large mental hospitals. J Abnorm Psychol. 1962; 64:349-60. doi: http://dx.doi.org/ 10.1037/h0045526

8. Santos SS, Soares MH, Hirata AGP. Attitudes, knowledge, and opinions regarding mental health among undergraduate nursing students. Rev Esc EnfermUSP.2013;4(5):1202-10.doi:http://dx.doi. org/10.1590/S0080-623420130000500026

9. Romano AMM, Pedrão LJ, Costa Júnior ML, Miasso AI. The impact of academic training on authoritarianism displayed by nursing students towards mental illness. Rev Enferm UFPE on line [Internet]. 2014 [cited 2017 Jul. 5]; 8(6):154552. Available from: http://www.revista.ufpe.br/ revistaenfermagem/index.php/revista/article/ viewArticle/5602

10. Gil IMA, Santos JCP, Loureiro LMJ. Estigma em estudantes de enfermagem: antes e depois do contato com pessoas com transtornos mentais. Rev Enferm UERJ. 2016; 24(1):1-7. doi: http:// dx.doi.org/10.12957/reuerj.2016.12309

11. Soares MH, Ruzzon ED, Bortoletto MSS. Conception of health professionals who work in emergency mental health. Rev Eletr Saúde Mental Álcool Drog. 2014; 10(2):85-92. doi: http://dx.doi. org/10.11606/issn.1806-6976.v10i2p85-92

12. Bennett J, Stennett R. Attitudes towards mental illness of nursing students in a Baccalaureate programme in Jamaica: a questionnaire survey. J Psychiatr Ment Health Nurs. 2015; 22(8):599605. doi: http://dx.doi.org/10.1111/jpm.12234
13. Gonçalves AM, Vilela SC, Terra FS, Nogueira DA. Attitudes and pleasure/suffering in mental health work. Rev Bras Enferm. 2016; 69(2):24553. doi: http://dx.doi.org/10.1590/0034$7167.2016690209 \mathrm{i}$

14. Tyson PJ. A service user-initiated project investigating the attitudes of mental health staff towards clients and services in an acute mental health unit. J Psychiatr Ment Health Nurs. 2013; 20(5):379-86. doi: http://dx.doi.org/10.1111/ j.1365-2850.2012.01929.x

15. Evans-Lacko SE, Henderson C, Thornicroft G. Public knowledge, attitudes and behaviour regarding people with mental illness in England 2009-2012. B J Psych. 2013; 202(55):51-7. doi: http://dx.doi.org/10.1192/bjp.bp.112.112979

16. Guimarães AN, Borba LO, Maftum MA, Larocca LM, Nimtz MA. Changes in mental health care due to the psychiatric reform: nursing professionals' perceptions. Ciênc Cuid Saúde. 2015; 14(1):830-8. doi: http://dx.doi.org/10.4025/cienccuidsaude. v14i1.22187

17. Gur K, Kucuk L. Females' Attitudes toward mental illness: a sample from rural Istanbul, turkey. Iran Red Crescent Med J [Internet]. 2016 [cited 2017 Jun 13]; 18(5):e22267. Available from: https://www.ncbi.nlm.nih.gov/pmc/articles/ PMC4950032/

18. Oliveira S, Carolino L, Paiva A. Programa saúde mental sem estigma: efeitos de estratégias diretas e indiretas nas atitudes estigmatizantes. Rev Port Enferm Saúde Mental [Internet]. 2012 [citado 2017 jun 13]; 8:30-7. Disponível em: http://www. scielo.mec.pt/pdf/rpesm/n8/n8a05.pdf

19. Maciel SC, Pereira CR, Lima TJS, Souza LEC. Desenvolvimento e validação da escala de crenças sobre a doença mental. Psicol Reflex Crit. 2015; 28(3):463-73. doi: http://dx.doi. org/10.1590/1678-7153.201528305

20. Costa LA,Almeida SC,Assis G. Reflexões epistêmicas sobre a Terapia Ocupacional no campo da Saúde Mental. Cad Ter Ocup UFSCar. 2015; 23(1):18996. doi: http://dx.doi.org/10.4322/0104-4931. ctoARL432 